\title{
EVALUATION OF KNOWLEDGE, ATTITUDE AND PRACTICES OF PARENTS TOWARD THEIR CHILDREN'S ORAL HEALTH COMPARED WITH THEIR DENTAL CARIES STATUS
}

\author{
Dikshit $P^{1^{*}}$, Limbu $S^{1}$, Gupta $S^{2}$, Pradhan $R^{3}$
}

\section{Affiliation}

1. Associate professor, Department of Pedodontics, Kantipur Dental College Teaching Hospital and Research Centre, Nepal.

2. Lecturer, Department of Periodontics, Kantipur Dental College teaching hospital and research centre, Nepal.

3. Dental Surgeon, Department of Pedodontics, Kantipur Dental College teaching hospital and research centre, Nepal.

\section{ARTICLE INFO}

Article History

Received : 25 May, 2018

Accepted : 20 August, 2018

Published : 31 August, 2018

(c) Authors retain copyright and grant the journal right of first publication with the work simultaneously licensed under Creative Commons Attribution License CC - BY 4.0 that allows others to share the work with an acknowledgment of the work's authorship and initial publication in this journal.

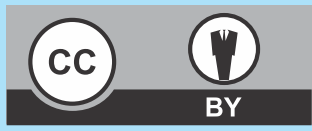

ORA 73

DOI: http://dx.doi.org/10.3126/bjhs.v3i2.20943

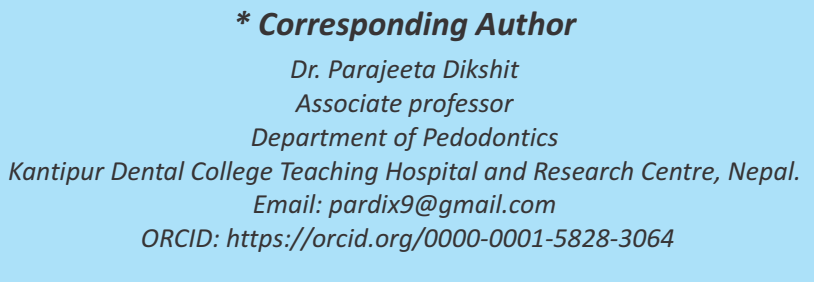

\section{Citation}

Dikshit P, Limbu S, Gupta S, Pradhan R. Evaluation of knowledge, attitude and practices of parents toward their children oral health compared with their dental caries status. BJHS 2018;3(2)6:447-452.

\section{ABSTRACT}

\section{Introduction}

Oral health is an integral component of overall health and well-being.Unfavorable oral hygiene habits cause early development of dental caries. Parents play a vital role in the oral health habits of their children. The oral care for the children can be improved by enhancing the oral health knowledge of their parents.

\section{Objectives}

The objective of this study was to find out the knowledge, attitude and practices of parents toward their children oral health compared with dental caries status.

\section{Methodology}

The sample consisting of 168 parent-child pair attending the Pedodontics department from November-December 2017 participated in the study after approval from Institutional review committee. A validated Nepali version of a structured questionnaire was used to collect the information on the knowledge, attitude and practice of the parents about oral health which was compared with the dental caries status of children and parents. The caries status was evaluated using the WHO criteria. The data was tabulated and subjected for statistical analysis.

\section{Results}

Most of the parents ( $89.3 \%$ ) were aware that dental caries was the most common dental disease affecting children. Around $57.7 \%$ knew the importance of fluoride in prevention of dental caries. The children had higher dental caries rate than parents which was statistically significant. The overall oral health knowledge and attitude of the parents was adequate but their practice was inadequate. Inadequate attitude and practice of the parents had statistically significant impact on the caries status of the child.

\section{Conclusions}

The parent's oral hygiene knowledge has an effect on their children oral health. So adequate education for parents is necessary to improve the influence of their dental health habits on their children's oral health.

\section{KEY WORDS}

Children; dental caries; knowledge; parents 


\section{INTRODUCTION}

Childhood, the golden period of life needs close monitoring for growth into a healthy adult. Good oral health boosts a child's confidence and allows them to eat, speak and socialize without experiencing any discomfort or embarrassment. ${ }^{1-3}$ Unfortunately children suffer from dental caries from an early age, an increase in prevalence occurs with the age. Improper oral hygiene is a major contributor of dental caries and children with poor oral hygiene are more likely to develop it. ${ }^{4}$

Parents are the primary decision makers for children and the first role models. Therefore, their oral health knowledge, attitude and practices as well as habits influence their children..$^{3-7}$ Appreciating and exploring the parental perception about their children oral health may help the dental community understand some of the reasons why children do not receive the dental care they need. ${ }^{1,6}$ One way to increase of oral health awareness among children would be to provide up-to-date oral health information, education and motivation to parents. ${ }^{8}$ Many research have highlighted the role of mother in child care while that of the father needs to be researched more. This study aims to determine the knowledge, attitude and practices (KAP) of parents toward their children's oral health and compared it with their dental caries status.

\section{METHODOLOGY}

A cross sectional study was conducted on 168 parents accompanying their 3 to 12 year old children to the Department of Pediatric Dentistry (Pedodontics), Kantipur Dental College for a routine dental check up from November to December 2017. Ethical clearance was obtained from Institutional Review Committee and informed consent was obtained from the study participants. The exclusion criteria were guardians other than parents and children with the presence of organic or psychiatric syndromes, systemic illnesses and severe in tellective or behavioral deficits.

A closed structured questionnaires on knowledge, attitude and practices (KAP) was adopted..$^{5}$ It was translated in Nepali by two dentists who were fluent in both English and Nepali. The Nepali version was then back translated into English by another two people fluent in both Nepali and English. The back translated version was compared with the English version to verify that the questions were properly translated. The questionnaire was filled by the parents in the waiting area of the department. It consisted of 28 questions, 10 related to knowledge, 6 to attitude, 8 to practices and 4 were general questions. The response was assessed by using a scoring system, where scores were based on correct answers. For the knowledge and practice items, the right answer was coded as 1 and the wrong answer as 0 . Attitude items were coded, score 1 indicated a positive attitude while score 0 indicated a negative attitude. The individual scores were then summed up to yield a total score.

Maximum possible score was 10, 6 and 8 for KAP respectively. Mean Score of $<40 \%$ and $\geq 40 \%$ were considered as inadequate and adequate performance respectively.

The oral assessment of each parent as well as child was done in the dental chair by two calibrated dentists. The dental caries status evaluation was based on WHO criteria for decayed, missing and filled teeth (DMFT / dmft). The DMFT scores were taken for the parents and dmft scores for children having deciduous teeth. In the mixed dentition, dmft and DMFT were recorded separately and the sum of both was used for each child.

The statistical package for social sciences (SPSS) version 20.0 was used to analyze the data. Descriptive statistics was carried out to calculate responses for each question and was set as frequencies and percentages. 2-tailed Independent ttest was used to compare the association between different variables and oral health knowledge, attitude and practices. The P-value was calculated under the predetermined level of significance of 0.05 at the confidence interval of $95 \%$.

\section{RESULTS}

There were 168 parent-child pair; children were categorized into 2 groups -3 to 6 years and 7 to 12 years while the parents were divided into 3 groups (20-30 years, $31-40$ years and $41-50$ years). The mean age of child was 7.59 years whereas that of parent was 35.06 years. There were more boys (59.5\%) among children and more mothers (61.9\%) as participants. (Table1) The responses of the participants to questions regarding oral health knowledge, attitude, practices and general questions are depicted in table 2, 3. The parents had adequate knowledge about oral health but their practice was inadequate (Figure 1) although there was no difference in the KAP between the mother and father (Table 4). The comparison of child and parents mean DMFT showed that the children had higher dental caries rate than

\begin{tabular}{ccccc}
$\begin{array}{c}\text { Table 1: Distribution according to Age Categories }(n=168) \\
\text { Age Category } \\
\text { (years) }\end{array}$ & $\begin{array}{c}\text { Male } \\
n(\%)\end{array}$ & $\begin{array}{c}\text { Female } \\
n(\%)\end{array}$ & $n(\%)$ & $\begin{array}{c}\text { Mean S.D. } \\
\text { (years) }\end{array}$ \\
$\begin{array}{c}\text { Children } \\
\text { 3-6 }\end{array}$ & $34(20.2)$ & $29(17.3)$ & $63(37.5)$ & $7.58 \pm 2.61$ \\
\hline $7-12$ & $66(39.3)$ & $39(23.2)$ & $105(62.5)$ & \\
\hline Total & $100(59.5)$ & $\mathbf{6 8 ( 4 0 . 5 )}$ & 168 & \\
\hline $\begin{array}{c}\text { Parent } \\
\mathbf{2 0 - 3 0}\end{array}$ & $11(6.5)$ & $36(21.4)$ & $47(28.0)$ & \\
\hline $\mathbf{3 1 - 4 0}$ & $36(21.4)$ & $56(33.3)$ & $92(54.8)$ & $35.06 \pm 6.10$ \\
\hline $\mathbf{4 1 - 5 0}$ & $17(10.1)$ & $12(7.1)$ & $29(17.3)$ & \\
\hline Total & $\mathbf{6 4 ( 3 8 . 1 )}$ & $\mathbf{1 0 4 ( 6 1 . 9 )}$ & $\mathbf{1 6 8}$ & \\
\hline
\end{tabular}


parents which was statistically significant. (Table 5). The comparison of knowledge, attitude and practice individually with Mean DMFT of child and parents was done using Independent t-test (2-tailed). It depicted that knowledge of parents did not alter the dental caries status. The parents who had inadequate attitude had children with statistically significant high levels of DMFT and higher caries rate was also found in children of parents with inadequate practice which was statistically significant. (Table 6)

Table 2: Responses of the participants to knowledge, attitude and practice $(n=168)$

Correct answer

$\mathrm{K} \quad$ 1. How many milk teeth are there in child's mouth ?

20

Yes

2. Does the tooth paste contain fluoride?

3. What is the role of the fluoride in the tooth paste ?

4. What is the most common dental disease in the child ?

5. Which of the food items can lead to tooth decay ?

6. Which do you think prevents tooth decay ?

7. Causes for gum disease?

8. Which do you think prevents gum disease?

9. Which can lead to irregular teeth?

10. Can irregularly placed teeth be aligned in correct position?

1. It is necessary to take child for regular dental visits.

2. Cleaning of child's mouth done/ supervised by parents.

3. It is necessary to clean the child's mouth after every meal.

4. Milk teeth do not require good care as it is going to fall.

5. Good oral health is related to good general health.

6. Healthy milk teeth are essential to chew food properly.

U

E

P

1. When do you take your child to visit the dentist ?

2. When did you start cleaning your child's teeth ?

A 3. Which of the following are used to clean your child's teeth?

C 4. How many times does your child's brush his teeth ?

T 5. When do you change your child's tooth brush?

I 6 What material does your child use to clean teeth?

C 7. Does your child rinse the mouth after eating/drinking ?

E 8. When do you give the sugary food to your child?
Prevents tooth decay

Tooth decay

All of the above

All of the above

All of the above

All of the above

All of the above

Yes

Agree

Agree

Agree

Disagree

Agree

Agree
68 (40.5)

$119(70.8)$

97 (57.7)

150 (89.3)

35 (20.8)

59 (35.1)

48 (28.6)

49 (29.2)

$40(23.8)$

147 (87.5)

96 (57.1)

$130(77.4)$

102(60.7)

80 (47.6)

$119(70.8)$

$108(64.3)$

Table 3: Responses of the participants to general questions $(n=168)$

\section{GENERAL QUESTIONS}

Answers

1. Source of information regarding oral health

A. Dentist

B. Pediatrician

C. Newspaper, TV

D. All of the above

E. Any other

2. How do you rate your child's oral health?

3. How may teeth are decayed in your child's mouth?

4. How are your child's teeth aligned? $n(\%)$

$\begin{array}{ll}\begin{array}{l}\text { Every } 6 \text { months } \\ \text { Soon after first milk } \\ \text { tooth eruption }\end{array} & 20(11.9) \\ \begin{array}{l}\text { Tooth brush } \\ \text { Once or twice in a day or }\end{array} & 64(38.1) \\ \text { after meal } & 95(56.5) \\ \text { Every 2-3 months/ } & \text { 65(38.7) } \\ \text { bristles fray out } & 54(32.1) \\ \text { Tooth paste } & 149(88.7) \\ \text { Yes } & 93(55.4) \\ \text { With meals } & 8(4.8)\end{array}$

19 (11.3)

$130(77.4)$

19 (11.3)

50(29.8)

57(33.9)

$35(20.8)$

26(15.5)

54(32.1)

$103(61.3)$

$11(6.6)$ 


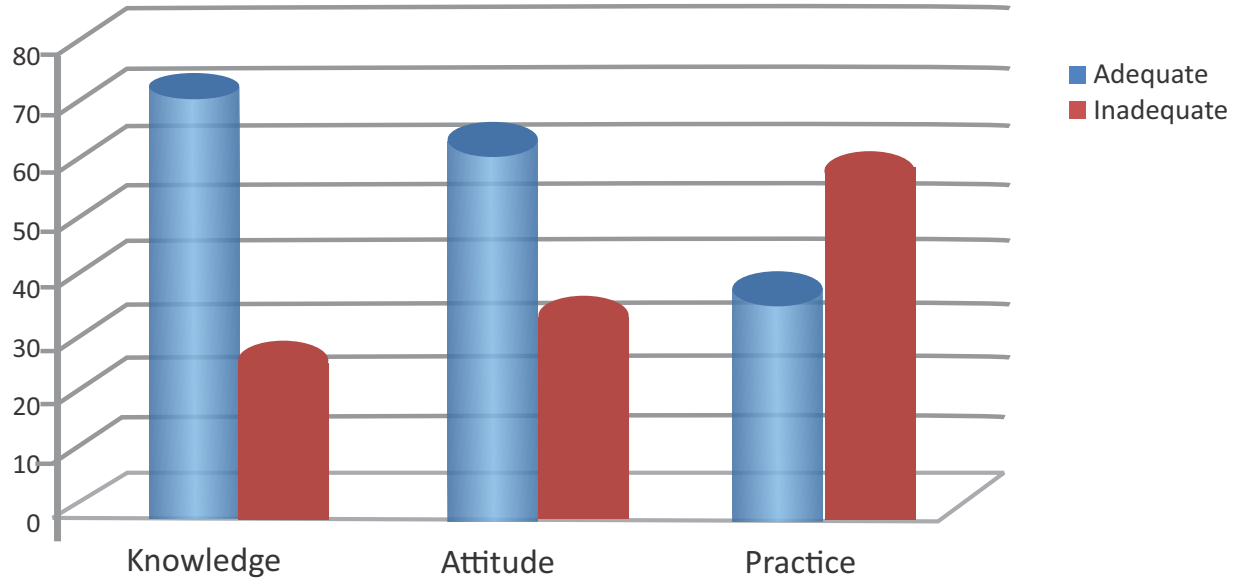

Figure 1: Adequacy of knowledge, attitude and practice in parents. $(n=168)$

\begin{tabular}{|c|c|c|c|c|c|c|}
\hline & & & Mean & $\begin{array}{l}\text { Standard } \\
\text { Deviation }\end{array}$ & $\begin{array}{l}\text { Standard } \\
\text { Error Mean }\end{array}$ & p-value \\
\hline \multirow[t]{2}{*}{ Knowledge Score } & Male & 64 (38.1) & 4.97 & 1.90 & 0.23 & \multirow[t]{2}{*}{0.469} \\
\hline & Female & 104 (61.9) & 4.75 & 1.89 & 0.18 & \\
\hline \multirow[t]{2}{*}{ Attitude Score } & Male & $64(38.1)$ & 4.05 & 2.01 & 0.25 & \multirow[t]{2}{*}{0.181} \\
\hline & Female & 104 (61.9) & 3.62 & 2.02 & 0.19 & \\
\hline \multirow[t]{2}{*}{ Practice Score } & Male & $60(38.1)$ & 3.05 & 1.30 & 0.16 & \multirow[t]{2}{*}{0.090} \\
\hline & Female & 104 (61.9) & 3.39 & 1.27 & 0.12 & \\
\hline
\end{tabular}

\begin{tabular}{|c|c|c|c|c|}
\hline & Mean & $\begin{array}{l}\text { Standard } \\
\text { Deviation }\end{array}$ & $\begin{array}{l}\text { Standard } \\
\text { Error Mean }\end{array}$ & $\begin{array}{l}\text { p-value } \\
\text { (2-tailed independent t-test) }\end{array}$ \\
\hline Parent's DMFT & 2.89 & 2.31 & 0.17 & $<0.001$ \\
\hline $\begin{array}{l}\text { Child's DMFT } \\
\text { (dmft/DMFT) }\end{array}$ & 6.33 & 3.66 & 0.28 & \\
\hline
\end{tabular}

Table 6: KAP of parents compared with DMFT $(n=168)$

$\begin{array}{llll}\text { n (\%) Mean } & \text { Standard } & \text { Standard } & \text { p-value(2-tailed } \\ & \text { Deviation } & \text { Error Mean } & \text { Independent t-test }\end{array}$

\begin{tabular}{|c|c|c|c|c|c|c|}
\hline \multirow[t]{2}{*}{ Knowledge } & Adequate & $123(73.2)$ & 2.89 & 2.32 & 0.21 & 0.98 \\
\hline & Inadequate & $45(26.8)$ & 2.89 & 2.31 & 0.34 & \\
\hline \multirow[t]{2}{*}{ Attitude } & Adequate & $109(64.9)$ & 2.81 & 2.18 & 0.21 & \\
\hline & Inadequate & $59(35.1)$ & 3.05 & 2.55 & 0.33 & \\
\hline \multirow[t]{2}{*}{ Practice } & Adequate & $67(39.9)$ & 2.79 & 2.10 & 0.25 & \\
\hline & Inadequate & $101(60.1)$ & 2.96 & 2.45 & 0.24 & \\
\hline \multicolumn{7}{|c|}{ Children's DMFT (dmft/DMFT) } \\
\hline \multirow[t]{2}{*}{ Knowledge } & Adequate & $123(73.2)$ & 6.13 & 3.41 & 0.30 & 0.30 \\
\hline & Inadequate & $45(26.8)$ & 6.87 & 4.28 & 0.63 & \\
\hline \multirow[t]{2}{*}{ Attitude } & Adequate & $109(64.9)$ & 5.20 & 2.97 & 0.28 & $<0.001$ \\
\hline & Inadequate & $59(35.1)$ & 8.41 & 3.93 & 0.51 & \\
\hline \multirow[t]{2}{*}{ Practice } & Adequate & 67 (39.9) & 5.31 & 3.28 & 0.40 & 0.003 \\
\hline & Inadequate & $101(60.1)$ & 7.00 & 3.77 & 0.37 & \\
\hline
\end{tabular}

\section{DISCUSSION}

The response rate of this hospital-based cross-sectional study was $100 \%$. The sex distribution of the children showed a high male to female ratio (1.47:1) similar to study by Hadeya $\mathrm{MH}$ et al $^{9}$, while that of parents showed a higher female to male ratio $(1: 1.62)$ highlighting the fact that more mothers accompany the child to the dentist. 
Around $40.5 \%$ parents in this study had the knowledge that the children have 20 teeth, $64.3 \%$ agreed that healthy teeth are required to chew food properly and it was necessary to take good care of the milk teeth although it is going to fall (47.6\%). Similarly Mubeen $\mathrm{N}$ et al found that $63 \%$ mothers and Oredungba F et al reported that $95.2 \%$ knew that primary teeth are important and should be taken care of, in their respective studies. ${ }^{10,11}$

Although $57.1 \%$ parents agreed that it was necessary to take child for regular dental visits but only $11.9 \%$ parents visited the dentist every 6 months. This was inconsistent with findings of Abeer A et al where the majority of mothers $(89.7 \%)$ reported that regular dental visits are not required. ${ }^{6}$ The barriers for regular visits as seen in the study may be apprehension, costly dental care, inaccessible dental clinics or lack of motivation.

Regarding questions on malaligned teeth , 23.8\% parents gave the correct answer for cause of malaligned teeth, $61.3 \%$ considered their child's teeth was not well aligned and $87.5 \%$ knew that irregular teeth can be aligned in correct position.

In regard to the question on knowledge of the parents regarding dental decay being the most common dental disease affecting children, most $(89.3 \%)$ responded correctly. This was in line with the other studies. ${ }^{5,6}$ The question on food items causing or preventing dental decay were answered correctly by $20.8 \%$ and $35.1 \%$ parents respectively. Only $28.6 \%$ and $29.2 \%$ knew the cause and prevention of gum diseases respectively. Oral hygiene knowledge and practices, response revealed that $38.1 \%$ parents started cleaning their child's teeth soon after eruption of the first one. This was in contrast to findings by $A$ beer $A$ et al where only $12.1 \%$ of mothers responded similarly. ${ }^{6}$ The reason for starting brushing later could be the lack of awareness or a fear that child will swallow tooth paste.

Parents used toothbrush (56.5\%) and toothpaste (88.7\%) to clean the teeth their child's teeth which was done twice a day or after meals by $38.7 \%$ participants. Around $70.8 \%$ stated that their toothpaste contained fluoride which prevented tooth decay (57.7\%). This was consistent with that of Oredungba $\mathrm{F}$ et al where $62.5 \%$ knew regular use fluoride toothpaste decreased tooth decay. ${ }^{11}$ Mubeen $\mathrm{N}$ et al gave a contrasting result where only one fourth of mothers stated that fluoride can prevent tooth decay. ${ }^{10}$ In our study it was found that $60.7 \%$ parents agreed that it is necessary to clean the child's mouth after every meal and $55.4 \%$ did rinse their mouth after eating. Many parents were in agreement $(77.4 \%)$ that cleaning of the child's mouth should be done or supervised by the parents. While in study by Mubeen $\mathrm{N}$ et al, majority of mothers did not know this need of parental assistance. ${ }^{10}$ Time of intake of cariogenic food plays an important role in dental caries it was sad to note that only few parents $(4.8 \%)$ gave sugary food at the proper time i.e. with meals. Suma $\mathrm{G}$ et al found that higher frequency of snacking was significantly associated with increased caries status in children. ${ }^{4}$

The major source of information about dental health for parents was the dentists (22\%), followed by Pediatrician (28\%) and Newspaper or Television (11.9\%). This was inconsistent with findings of Jain $\mathrm{R}$ et al and Oredungba $\mathrm{F}$ et al, where most information was from newspapers and TV $(45 \%)$ as compared to others medium. ${ }^{5,11}$ This difference could be because the subjects in the present study filled the questionnaire in the dental setting.

When asked about their child's decayed teeth, $29.8 \%$ reported $<3$ decayed teeth, 33.9\% stated 3-6 and 20.8\% responded $>6$ while $15.5 \%$ had not checked decay in their child's mouth. Jain R et al reported a different finding where around 51\% mothers reported $<3$ decayed teeth, $24.2 \%$ reported 3-6 decayed teeth, $4.5 \%$ reported $>6$ decayed teeth and $20.1 \%$ were not aware about it. ${ }^{11}$

Overall the parents in the present study had adequate knowledge about oral health of their child but their practice was inadequate.

The mean DMFT of the children were 6.33 while that of the parents was 2.89 and this difference was statistically significant. In some studies, parental beliefs and attitudes towards oral health have been associated with caries development in children. Wigen and Wang on comparing KAP with the dental caries status found that adequate or inadequate knowledge did not influence the DMFT of parents or child. ${ }^{12}$ The mean DMFT of children with parents who had adequate attitude i.e. more positive towards oral health were less than that of children whose parents had inadequate attitude. This comparison was statistically significant. This was in line with study conducted by Z Saied et al. ${ }^{13}$ The parents who practiced adequate oral health had children with less mean DMFT which statistically significant.

\section{CONCLUSIONS}

Parent's knowledge of oral hygiene has an influence on their child's oral health. Children begin their learning from home and inculcate the habits and practices of their parents. It is therefore necessary for parents to adopt good oral health knowledge and practices.

\section{RECOMMENDATIONS}

The study recommends Oral health counseling to be conducted to all parents attending the dental clinic with their child.

\section{LIMITATION OF THE STUDY}

The study was carried out in a hospital where only a representation of the population were seen. The sample size is small and therefore cannot be generalized to the entire population.

\section{ACKNOWLEDGEMENT}

We would like to thank all participants of the present study and staff of Department of Pediatric Dentistry, Kantipur Dental College.

\section{CONFLICTS OF INTEREST}

None

\section{FINANCIAL DISCLOSURE}

None 


\section{REFERENCES}

1. Farid $\mathrm{H}$, Khan FR, Aman N. Knowledge, attitude and practice of mothers regarding their own and children's dental health-a tertiary care hospital based study .J Ayub Med Coll Abbottabad 2013;25( 34):35-7.

2. Vasanthakumari A, Vivek K., Vivek Reddy., Jai Ganesh I, Lokesh S. Mother's Knowledge And Awareness On Promoting Children's Dental Health. International Journal Of Recent Scientific Research. 2017; 8(12): 22842-44. DOI: 10.24327/IJRSR.

3. Bennadi D, Reddy CVK, Sunitha S, Kshetrimayum N. Oral Health status of 3-6 year old children and their mother's oral health related knowledge, attitude and practices in Mysore City, India. Asian Journal of Medical Sciences. 2015; 6 (2):66-71.DOI:10. 3126/ajms.v $6 \mathrm{i} 2.11097$.

4. Suma $G$ and Anisha P. Evaluation of the Association of Parent's Oral Health Knowledge and Development of Dental Caries in their Children. Austin J Dent. 2017; 4(7): 1092.DOI:10.26420/austinjdent. 2017.1092.

5. Jain R, Oswal KC, Chitguppi R. Knowledge, attitude and practices of mothers toward their children's oral health: A questionnaire survey among subpopulation in Mumbai (India). J Dent Res Sci Develop 2014; 1:40-5. DOI: 10.4103/2348-3407.135073.

6. Abeer A. Al-Oufi,Ola M. Omar.Oral Health Knowledge and practices of mothers toward their children's oral health in Al Madinah. BJMMR 2016, 15(10): 1-10.DOI:10.9734/BJMMR/2016/26113.
7. Al-Zahrani AM, Al-Mushayt AS, Otaibi MF, Wyne AH. Knowledge and attitude of Saudi mothers towards their preschool children's oral health. Pak J Med Sci 2014; 30(4):720-724.DOI:http://dx.doi. org/10.12669/pjms.304.5069.

8. Bondarik Elena, Leous Petr. Oral Health and Children Attitudes Among Mothers and School teachers in Belarus.Stomatologija, Baltic Dental and Maxillofacial Journal. 2004; 6(2).

9. Hadeya MH, Amal HA. Parental Oral health knowledge, attitude, practice and caries status of Sudanese cerebral palsy children. Ped Health Res 2017;2(2):1-8. DOI:10.21767/2574-2817.100015.

10. Mubeen N, Nisar N. Mother's knowledge, attitude and practices regarding dental caries and oral hygiene among children (Age 1 To 5 Years) in Civil hospital, Karachi. Int J Dent Oral Health 2015;2(4). DOI:10.16966/2378-7090.165.

11. Oredugba, F., et al. Assessment of Mothers' Oral Health Knowledge: Towards Oral Health Promotion for Infants and Children. Health 2014; 6: 908-915.http://dx.doi.org/10.4236/health.2014.610114.

12. Wigen TI, Wang N J. Parental influences on dental caries development in preschool children. An overview with emphasis on recent Norwegian research. Norsk Epidemiologi 2012; 22(1): 13-19. DOI:https://doi.org/10.5324/nje.v22i1.1515.

13. Z. Saied-Moallemi, J.I. Virtanen, Ghofranipour F, Murtomaa H Influence of mothers' oral health knowledge and attitudes on their children's dental health.European Archives of Paediatric Dentistry 2008; 9(2):79-83.DOI:10.1007/BF03262614. 